\title{
ARQUITECTURA AMAZÓNICA Y PERCEPCIONES DE FRONTERA: ESTUDIO DE CASO BARRIOS LA UNIÓN Y GUADALUPE EN LAS CIUDADES GEMELAS DE LETICIA Y TABATINGA*
}

Erik Vergel Tovar**

El artículo presenta hallazgos relacionados con la producción de arquitectura y las percepciones acerca de la frontera por parte de habitantes de los barrios La Unión (Leticia, Colombia) y Guadalupe (Tabatinga, Brasil), los cuales hacen parte de los resultados de la investigación: te de los resultados de la investigación: Borders, an Appropriate Cross Border Approach for Squatter Settlements on flood prone lands located on border's fringe: The Case Study of Leticia and Tabatinga.

* Los puntos de vista aquí expresados son del autor, no representan ni pueden atribuirse a la entidad para la cual trala cual trabaja.

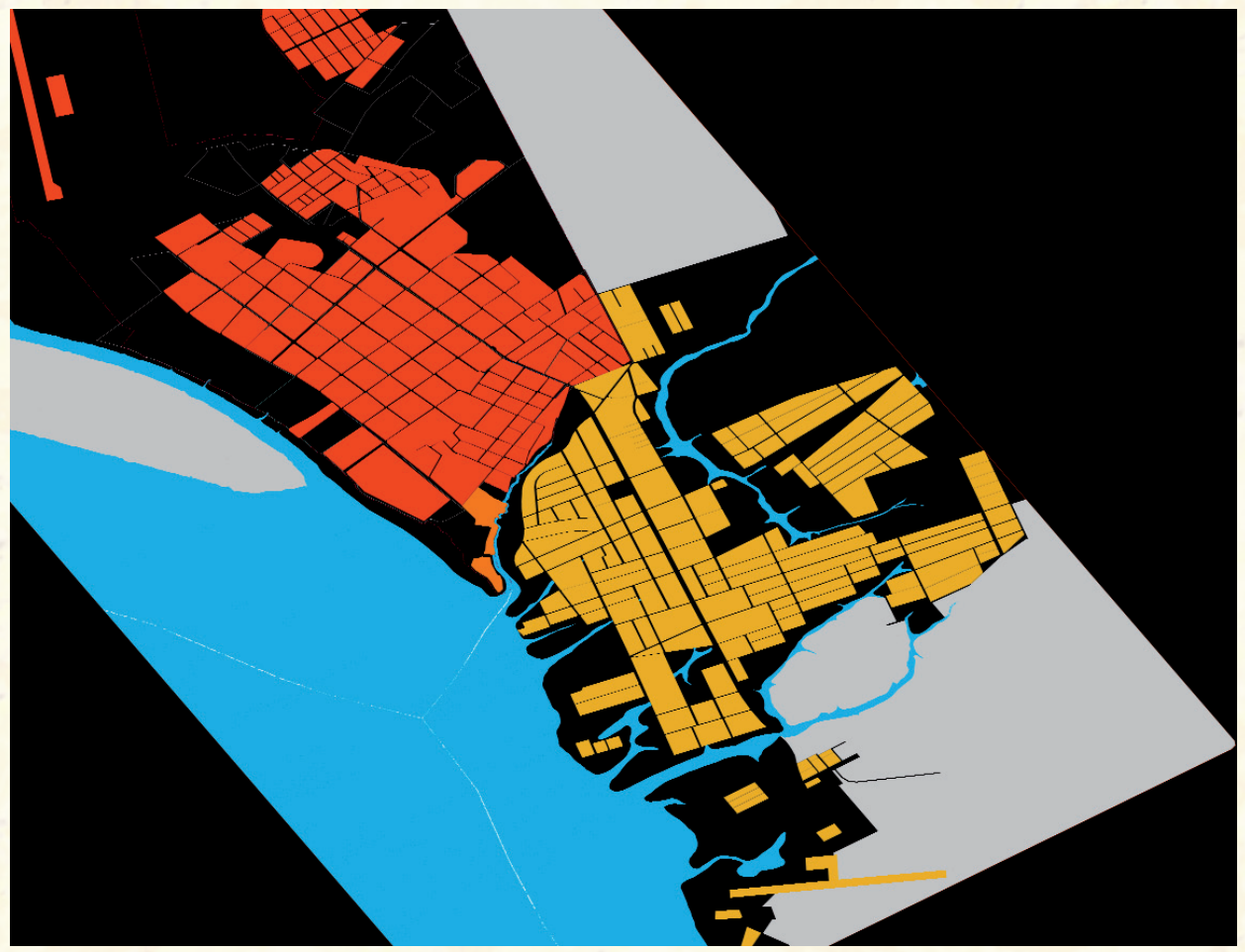

\section{RESUMEN}

El artículo se enfoca en la producción de arquitectura para la vivienda por parte de los habitantes de dos asentamientos precarios localizados en la franja de frontera conformada por la Quebrada San Antonio en las ciudades gemelas de Leticia (Colombia) y Tabatinga (Brasil); así mismo, describe las percepciones de los habitantes fronterizos acerca de la condición de vivir en la frontera. El artículo desarrolla un estudio comparativo en busca de aspectos simétricos y asimétricos a través del análisis de los patrones de ocupación de los dos asentamientos barrios, las características socioeconómicas de sus habitantes, tipologías de viviendas y la adaptación a los periodos de inundación. Además, el artículo muestra cómo los habitantes fronterizos están transformando el límite en un espacio social del territorio.

\section{PALABRAS CLAVE}

Arquitectura, Fronteras, Asentamientos Precarios, Vivienda, Amazonía, Cooperación Transfronteriza, Ciudades gemelas, Zonas inundables. 


\title{
AMAZONIAN ARCHITECTURE AND BORDERLANDER 'S PERCEPTIONS: CASE STUDY OF LA UNION AND GUADALUPE NEIGHBORHOODS IN THE TWIN CITIES OF LETICIA AND TABATINGA
}

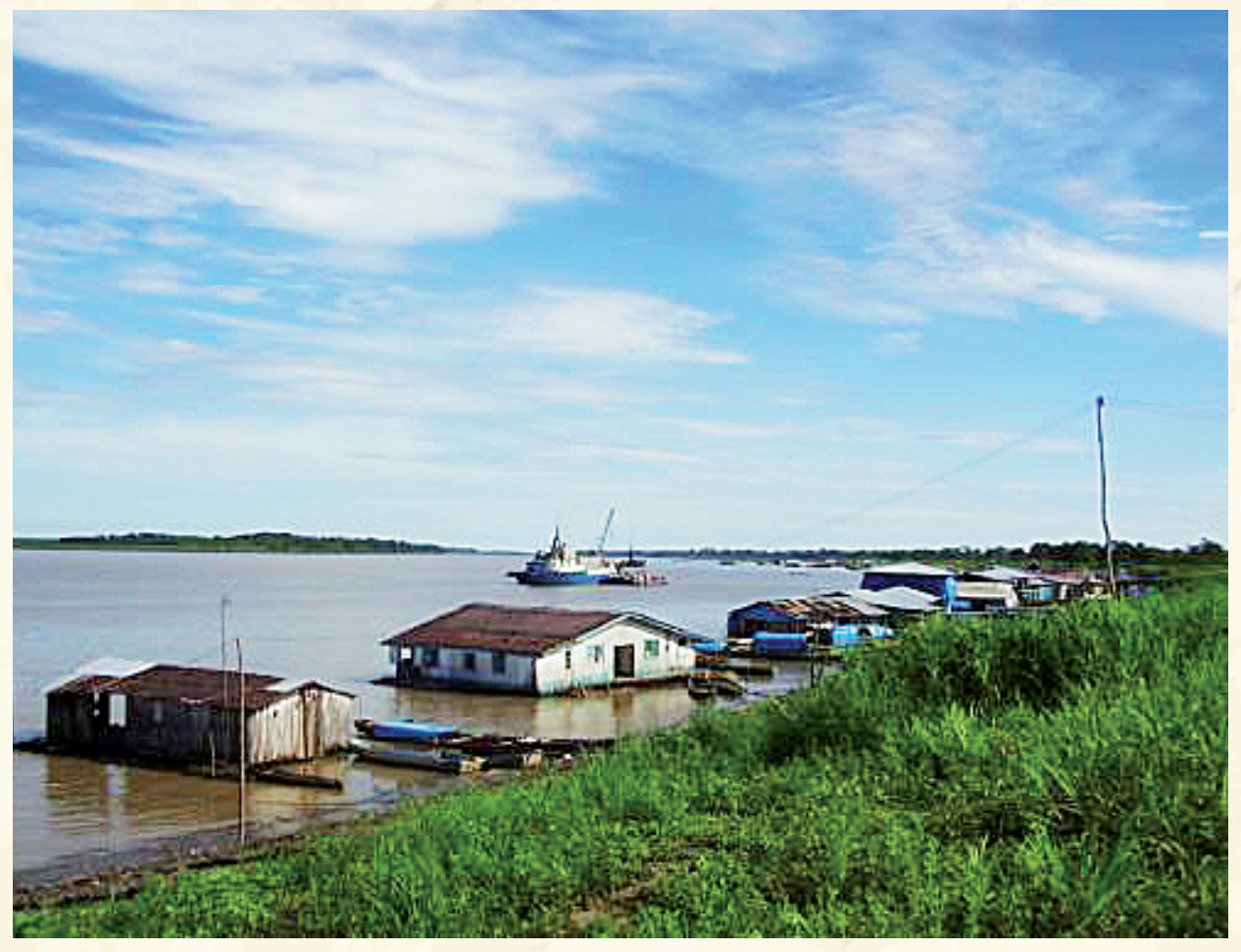

\begin{abstract}
The paper focuses the topic of architecture developed for housing by borderlanders in two squatter settlements located along the border fringe conformed by the San Antonio 's Ravine in the twin cities of Leticia (Colombia) and Tabatinga (Brazil; likewise, it describes the borderlanders perceptions regarding the condition of living in the border. The paper develop a comparative study looking for symmetric and asymmetric issues by analyzing land occupation patterns, socioeconomic characteristics, housing typologies and adaptation to the flooding periods. In addition, the paper shows how the borderlanders are transforming the limit towards a social spatial construction.
\end{abstract}

\section{KEY WORDS}

Arquitecture, Borders, Squatter Settlements, Housing, Amazon, Cross border cooperation, Twin Cities, Flood prone lands. 


\section{INTRODUCCIÓN}

\section{I.I Antecedentes}

La realidad de los territorios fronterizos siempre plantea retos en los ejercicios de planeación urbana y ordenamiento territorial, no sólo para las autoridades locales sino también para los habitantes que construyen estos territorios como parte de su vida cotidiana. En este contexto, la aproximación a esta realidad plantea grandes esfuerzos para comprender las dinámicas locales y desde una perspectiva institucional poder entrar a "regularlas" desde los instrumentos que establecen el marco legal para el ordenamiento territorial y las zonas de frontera. De esta forma, varias preguntas emergieron durante el proceso de apoyo a municipios de las regiones Orinoquia y Amazonía, en el marco del programa de asistencia técnica del Ministerio de Ambiente Vivienda y Desarrollo Territorial, en el proceso de asistencia técnica dirigida a los municipios en procesos de revisión y ajustes de sus respectivos Planes de Ordenamiento Territorial POT, específicamente en el municipio de Leticia en el Departamento del Amazonas. El autor estuvo vinculado con dicho proceso a través de mesas de trabajo, visitas de campo, interacción con las comunidades asentadas y con miembros de la comunidad académica de la Universidad Nacional de Colombia, Sede Amazonía durante los años de 2004 y 2005.

En este sentido, dichas preguntas se constituyeron en el principal insumo para adelantar la investigación "Ciudades Gemelas en fronteras amazónicas, una estrategia apropiada para el manejo de asentamientos precarios en zonas inundables localizados en franjas de frontera: estudio de caso Leticia y Tabatinga", en el marco del estudio de Maestría adelantado por el autor del presente artículo. Esta investigación partió de la necesidad de analizar la ciudad de Leticia en conjunto con la ciudad de Tabatinga (Brasil) debido al proceso de conurbación que llevó a las dos ciudades a constituirse en una sola aglomeración urbana. El caso de las ciudades de Leticia y Tabatinga se constituye en un claro ejemplo de una conurbación binacional en la rivera del Amazonas, en donde la integración se da en distintos niveles y aspectos. No obstante, la investigación se enfocó en el tema de los asentamientos precarios localizados en la franja de frontera que une y separa al mismo tiempo a las ciudades de Leticia (Colombia) y Tabatinga (Brasil).

La investigación contó con el apoyo del Institute for Housing and Urban Development Studies IHS, la Universidad de Lund en Suecia, y la Universidad Nacional de Colombia, Sede Amazonía. Posterior a la sustentación final de los resultados de la investigación en la ciudad de Rotterdam, (Holanda), los resultados de la investigación se han presentado en el Coloquio "Ciudad, periferia urbana y habitabilidad: reflexiones sobre la construcción de la ciudad colombiana" organizado por el Instituto Javeriano de Vivienda y Urbanismo INJAVIU en el año 2007, y en el mes de la investigación organizado por la Universidad Nacional de Colombia, Sede Amazonía, durante el mes de noviembre de 2008 en la ciudad de Leticia.

El presente artículo desarrolla entonces aspectos de la investigación relacionados con la producción de arquitectura por parte de los habitantes fronterizos, sus percepciones acerca de la frontera así como el avance en algunas reflexiones y aspectos emergentes de la investigación que se constituyeron en insumos en el trabajo del autor en procesos de formulación de políticas, programas y proyectos. 


\section{I.2 El fenómeno de la urbanización en la región amazónica y las ciudades gemelas de Leticia y Tabatinga}

En el contexto de un mundo urbanizado, las ciudades latinoamericanas han estado experimentando un rápido crecimiento urbano sin precedentes. La región Amazónica localizada al norte de Suramérica no escapa a este fenómeno' como parte de la tendencia en cuanto al crecimiento de la población urbana, el cual es referido para el contexto amazónico como la "selva urbanizada". En este contexto, el proceso de urbanización en la región amazónica conocido como "el anillo de poblamiento" 2 , ha transformado la romántica idea de la selva intocable y pulmón del mundo, en una realidad urbana compuesta por una red de ciudades y asentamientos humanos que ejercen presión sobre los recursos naturales del bosque húmedo tropical. Hoy en día la "selva urbanizada" es un fenómeno con pocos estudios urbanos e investigaciones en comparación con la magnitud del proceso de urbanización, que permitan comprender mejor la Gran Amazonía del siglo XXI (Becker, B., 1995).

La región amazónica abarca 6 países: Bolivia, Brasil, Colombia, Ecuador, Perú y Venezuela. Cada país ha reflejado las mismas dinámicas de crecimiento poblacional en las áreas urbanas localizadas al interior de la Amazonía a través de dos procesos paralelos: i) una fuerte presión sobre el ecosistema del bosque húmedo tropical a través de una gran red de asentamientos humanos alrededor de la región e interconectados con los sistemas viales nacionales de cada país; y, ii) a través de aquellos asentamientos humanos localizados al interior de la Amazonía, los cuales están intercomunicados sólo a través de las redes fluviales o los servicios de transporte aéreo con las ciudades principales (SINCHI, 2005).

En estos países pertenecientes a la Gran Cuenca Amazónica, el proceso de consolidación de estas estructuras urbanas y regionales representa un gran reto debido a su relación con las dinámicas generadas por diferentes actividades económicas conocidas como "boom o bonanzas" 3 , las cuales han servido como el mejor motor para mantener las tendencias de crecimiento urbano. Así mismo, tanto el "boom" de la biodiversidad como el del turismo en la Amazonía ha generado un gran interés por parte de las empresas multinacionales y los países de altos ingresos que se encuentran en la búsqueda de nuevos recursos naturales y espacios nuevos que visitar, intereses para los cuales el bosque húmedo tropical puede brindar importantes recursos como espacios para futuros desarrollos.

En este contexto, los territorios fronterizos considerados por algunos como "espacios olvidados" han contado con el surgimiento de áreas urbanas que en parte deben su desarrollo a la necesidad de los Estados-Nación de ejercer presencia en dichos territorios. Lo anterior, ha convertido al Estado en el principal empleador en los territorios fronterizos a través de entidades gubernamentales, instalaciones militares, gobiernos regionales y locales, por consiguiente, estas entidades se constituyen en la principal "presencia" estatal en los territorios fronterizos. En el caso específico de la frontera entre Colombia y Brasil, tenemos el caso de varias áreas urbanas que en algunos casos presentan una ciudad par o gemela al otro lado del límite fronterizo, las cuales presentan diferentes niveles de urbanización y jerarquía en concordancia con el tamaño y las interacciones transfronterizas que allí se generan (Tabla I).
La población en Latino América y el Caribe en 1990 era de 441 millones de habitantes, de los cuales 315,4 millones vivían en zonas urbanas. Para 2005, se estima que la población de Latino América y el Caribe ascendió a 546.3 millones de habitantes con 420.7 millones en áreas urbanas. (UNHABITAT 1996, An Urbanizing World. Informe Mundial sobre los Asentamientos Humanos)

2 Instituto SINCHI. Perfiles Urbanos de la Amazonía Colombiana, 2005.

3 La Gran Amazonía ha sido objeto de diferentes actividades extractivas durante el siglo $X X$, inicialmente con "caucho", pasa por a "coca" asociada "caucho", pasa por la "coca" asociada a "petróleo" y recientemente la "produc ción de energía". 
Tabla I. Ciudades Gemelas Amazonía Colombiana y Brasilera

\begin{tabular}{|c|c|c|}
\hline \multicolumn{3}{|c|}{ Ciudades Gemelas A mazonía Brasilera } \\
\hline País & Lado Brasilero & País Vecino \\
\hline $\begin{array}{c}\text { GUYANA } \\
\text { FRANCESA }\end{array}$ & Oiapoque & Saint Georges \\
\hline GUYANA & Bonfim & Lethem \\
\hline VEN EZUELA & Santa Elena & Pacaralma \\
\hline COLOMBIA & Tabatinga & Leticia \\
\hline \multirow{3}{*}{ PERÚ } & Benjamin Constant & Islandia \\
\hline & Santa Rosa do Purus & Santa Rosa \\
\hline & Iñapari/Assis & Bolpebra \\
\hline BOLIVIA & Brasiléia & Cobija \\
\hline \multicolumn{3}{|c|}{ Ciudades Gemelas A mazonía Colombiana } \\
\hline País & Lado Colombiano & País Vecino \\
\hline ECUADOR & San Miguel (Putumayo) & Lago Agrio \\
\hline \multirow{3}{*}{ PERÚ } & El Encanto (Amazonas) & El Estrecho \\
\hline & Puerto Alegría (Amazonas) & Yubineto \\
\hline & Puerto Nariño (Amazonas) & Caballococha \\
\hline \multirow{3}{*}{ BRASIL } & Leticia (A mazonas) & Tabatinga (Amazonas) \\
\hline & Tarapacá (Amazonas) & Ipiranga \\
\hline & La Pedrera (Amazonas) & Villa - Betancur \\
\hline
\end{tabular}

Fuente: Grupo RETIS (Universidade Federal do Rio do Janeiro FRJ), Perfiles Urbanos de la Amazonía Colombiana. (Instituto $\mathrm{SINCHI}$ de Investigaciones Amazónicas). Elaboración propia.

Dentro de este grupo de asentamientos humanos a lo largo de la frontera colombo brasilera, se destaca el caso de las ciudades de Leticia (Colombia) y Tabatinga (Brasil), en la frontera entre ambos países al costado norte de la rivera del Amazonas, debido a que ambas áreas urbanas han crecido en un proceso paralelo como ciudades hermanas hasta el punto de conurbarse y de esta forma constituirse en las denominadas por algunos autores "ciudades gemelas". Así mismo, este crecimiento urbano se caracteriza por presentar dos tipos de asentamiento diferentes, la ciudad de Leticia ha crecido con un patrón urbano en "damero" español, mientras que Tabatinga ha crecido con un patrón urbano “militar” portugués (Mapa I, Vergel, E., 2006).

Mapa I. Estructura Urbana Ciudades Gemelas Leticia y Tabatinga

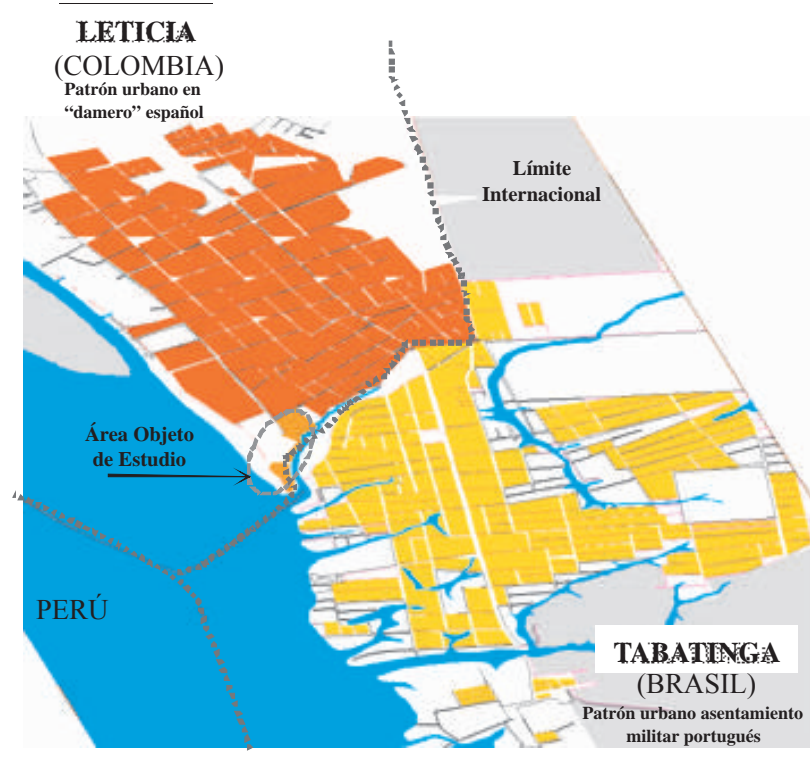

Fuente: Elaboración propia del autor (2006). 
El crecimiento urbano de ambas ciudades se debe al rápido crecimiento poblacional durante las décadas del 70 y 80 , el cual generó un gran impacto en la extensión de ambas ciudades hacia su conurbación. Si bien este denominado "boom" poblacional tuvo lugar por el impacto de las actividades ilícitas y extractivas en la región, recientemente el desarrollo urbano de las ciudades ya conurbadas ha estado caracterizado por actividades relacionadas con el denominado "ecoturismo", especialmente a lo largo del "eje turístico amazónico" conformado por lquitos (Perú), Manaus (Brasil) y Belem Do Para (Brasil). Las ciudades de Leticia y Tabatinga se encuentran sobre dicho eje, aproximadamente en la mitad del recorrido fluvial desde la ciudad de lquitos y la ciudad de Manaus.

Las ciudades gemelas de Leticia y Tabatinga debido a la conurbación han enfrentado algunos problemas urbanos compartidos tales como la alta contaminación de cuerpos de agua, incremento en los niveles de polución, bajas coberturas de agua potable y saneamiento básico, ausencia de tratamiento de aguas residuales, desarticulación del servicio de transporte público urbano y formación de asentamientos precarios en zonas inundables. Este último se debe principalmente al alto déficit habitacional en ambas ciudades y la baja capacidad en la generación de oferta de vivienda frente al alto crecimiento poblacional en la última década.

Aunque el nivel de conocimiento acerca del proceso de urbanización en la Gran Amazonía es muy bajo, en el caso de Leticia y Tabatinga se han desarrollado estudios urbanos recientemente que contribuyen a comprender su dinámica transfronteriza. Por lo tanto, el presente artículo explora aspectos no publicados de la investigación realizada en 2006 , específicamente en cuanto a la producción de arquitectura amazónica para la vivienda, las percepciones de frontera por parte de los habitantes del área objeto de estudio, y las implicaciones que ha tenido el estudio en la formulación de políticas, programas y proyectos.

\section{MARCO TEÓRICO ${ }^{4}$}

\section{I Ciudades Pares, Fronterizas, Transfronterizas y Ciudades Gemelas}

En el mundo contemporáneo donde las redes, flujos y comunicaciones de información, capitales y personas cada vez presentan un mayor desarrollo, crecimiento y velocidad, el estudio de las fronteras y territorios fronterizos se ha constituido en un campo de investigación más amplio. Precisamente las áreas urbanas localizadas en los territorios fronterizos se caracterizan por concentrar la mayor parte de flujos e intercambios transfronterizos $y$, por consiguiente, estas zonas han ganado un mayor protagonismo no sólo en la investigación, sino también en la agenda de los Estados-Nación que buscan ejercer presencia en estos territorios así como regular dichas dinámicas. Adicionalmente, las áreas urbanas localizadas a lo largo de los territorios fronterizos o ciudades fronterizas han ganado mayor atención por diferentes disciplinas, tales como las ciencias sociales y políticas, especialmente en Europa Occidental debido a los esfuerzos de integración por parte de los países europeos en el marco de la Unión Europea UE. Así mismo, al profundizar en el tema de las ciudades fronterizas existe un campo de especial interés en los territorios fronterizos, el cual consisten precisamente en el fenómeno de las ciudades dobles entendidas como un par de ciudades de

\footnotetext{
4 El presente marco teórico retoma y complementa las definiciones elaboradas por el autor en el artículo "Ciudades Gemelas en Fronteras Amazónicas: Estudio de Caso Leticia y Tabatinga", Cuadernos de Vivienda y Uanatisu dad Javeriana (2009), específicamente en relación con la aproximación conceptual acerca de las ciudades gemelas y el concepto de frontera.
} 
5 Ehlers, N., Buursink, J., Boekema, F. 200I, Introduction: Binational cities and their regions: From diverging cases to a common research agenda, Geojournal $54: 1-5$

6 En este caso el concepto de territorialización es entendido como los aspectos que ocurren en un territorio específico transformados en hechos concretos por los habitantes de territorios fronterizos que influyen en este espacio a través de diferentes flujos.

7 En este caso el concepto de EstadoNación es entendido como el proyecto del Estado Moderno en el cual éste tiene el poder y establece la regulación para toda la nación. El concepto de Estado-Nación en estudios de frontera es crucial porque "la incapacidad de los gobiernos en el mundo contemporáneo para controlar el trafico de personas, bienes información a través de sus fronteras est cambicion la naturalezo de los Estado". (Anderson M. 1996). 8 lbíd. similar tamaño que están localizadas muy cerca la una de la otra (Ehlers, Buursink and Boekema, 200I)5.

Tal es el caso de los estudios de fronteras que se han constituido de especial interés entre políticos e investigadores debido al proceso de territorialización ${ }^{6}$ que ha tenido lugar en las áreas fronterizas a través del flujo de personas en las redes generadas, lo cual implica un nuevo reto para los Estados-Nación ${ }^{7}$, puesto que las fronteras han dejado de ser zonas de restricción y control para convertirse en áreas de intercambio comercial y alta rentabilidad entre países (Machado, 1998). Las ciudades localizadas en territorios fronterizos han ganado mayor protagonismo en la agenda de los Estados-Nación debido a que son el punto de encuentro más importante entre países vecinos y de intercambio entre uno y otro; por consiguiente, el concepto de ciudades gemelas se ha posicionado de manera importante para nombrar a las ciudades pares localizadas en territorios fronterizos que establecen un diálogo reciproco permanente. De acuerdo con el Diccionario Chamber, ciudad gemela es definida como: "una ciudad par con otra de un país extranjero de tamaño similar, establecida con el propósito de intercambios sociales, culturales y comerciales"8.

La coexistencia de ciudades gemelas o pares puede generar problemas comunes para ambas áreas urbanas, los cuales pueden ser resueltos a través de escenarios de cooperación entre ambas ciudades. No obstante, la coexistencia puede también generar un conflicto de intereses entre ambas ciudades, el cual puede llevar a escenarios de competencia entre una y otra. Es importante destacar que estos dos escenarios son uno de los aspectos más importantes de estudio en ciudades gemelas o pares, debido a que la coexistencia de este tipo de ciudades plantea la existencia de una relación entre ambas, no sólo a nivel gubernamental, sino también entre la población que habita los territorios fronterizos. Por lo anterior, los estudios urbano-regionales que se desarrollen en ciudades fronterizas no sólo requieren involucrar a los gobiernos locales, instituciones y organizaciones, sino también a la población y comunidades allí asentadas, éstos últimos son los que precisamente generan los espacios sociales que determinan las relaciones y sinergias que puedan llevar hacia una futura integración en la resolución de problemas comunes.

Existen algunos aspectos principales a tener en cuenta en los estudios de ciudades gemelas para encontrar una paridad real. Esto incluye el origen de las áreas urbanas, año de fundación y el motivo de crear un asentamiento humano en esa zona, el tamaño físico y poblacional, apariencia en términos del medio ambiente construido, entidades gubernamentales e institucionales locales, las características socioeconómicas de la población y su cultura local. Considerando estos aspectos es posible hacer un análisis de ciudades gemelas que presentan relaciones transfronterizas; no obstante, de acuerdo con Buursink, existen tres aspectos diferentes entre este tipo de ciudades: i) físicos o paisaje del medio ambiente construido, este define las características de la arquitectura de la ciudad, espacios públicos, la relación con el medio ambiente natural, y la ciudad como producto de una cultura, clima e historia local; ii) marco institucional, identificación de las diferentes organizaciones, instituciones que juegan un papel importante en las relaciones entre ambos lados de la frontera, las cuales se constituyen en las potenciales instancias de cooperación para resolver dificultades comunes; y iii) 
la ciudad como comunidad, la nacionalidad y lugar de origen pueden determinar relaciones, interacciones sociales y sentimientos de pertenencia, así como la realidad social en ciudades fronterizas como resultado de las experiencias en la vida diaria en zonas periféricas. Aunque estos aspectos son útiles en la definición de ciudades fronterizas o ciudades gemelas, existe una gran discusión acerca de la definición de este tipo de áreas urbano regionales. Al momento de utilizar conceptos tales como ciudades binacionales o ciudades gemelas por parte de distintos actores como los distintos niveles de gobierno, instituciones en busca de estrategias de mercadeo y relaciones comerciales, entidades en busca de recursos financieros por parte de donantes ó simplemente por parte de aquellas organizaciones que se encuentran en la búsqueda de su propia identidad.

Para Buursink la ciudad binacional no es un concepto apropiado para aquellas ciudades que están localizadas en diferentes países impidiendo la posibilidad a cada una de ser parte del país vecino, en sus términos "ciudades transfronterizas" es el mejor nombre para las ciudades pares o fronterizas, porque ambas ciudades subsisten en los contactos transfronterizos e inspiradas por intereses comunes $y$ oportunidades atractivas debido a su condición. Aunque el concepto de ciudades gemelas para él no tiene sentido debido a que el concepto "gemelas" quiere decir que ambas ciudades son idénticas con un fuerte sentimiento de pertenencia entre ambas, otros autores plantean que este concepto si es apropiado en la medida en que dichas ciudades pueden presentar aspectos simétricos y asimétricos (Diagrama 2).

Diagrama 2. El concepto de Ciudades Gemelas

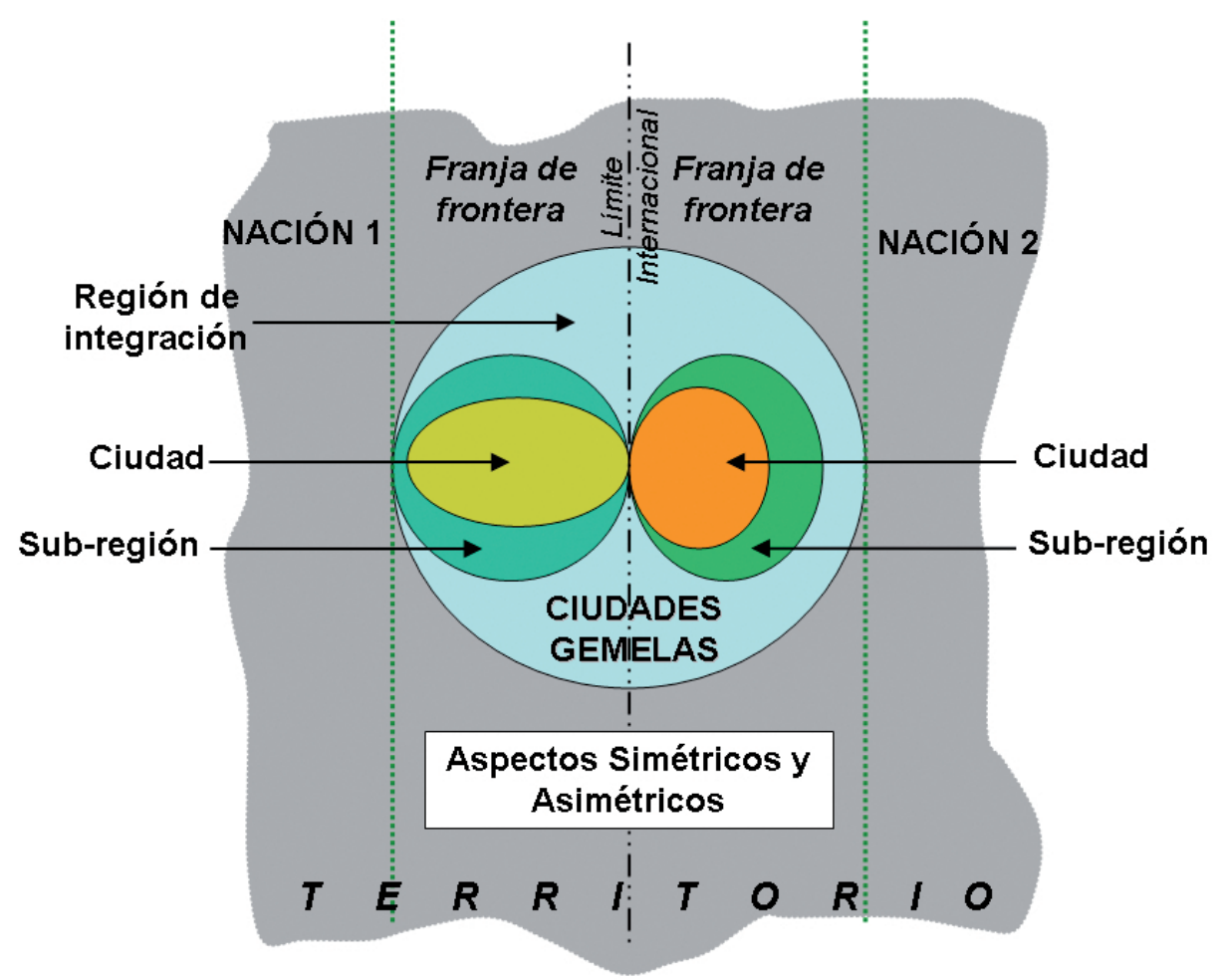

Fuente: Propuesta de re-estructuración para el Programa de Desarrollo de Franjas de Frontera. Ministerio de la Integración, Gobierno Federal del Brasil. Pág. 22. Fuente: Adaptado de Vergel, E. "Ciudades Gemelas en Fronteras Amazónicas: Estudio de Caso Leticia y Tabatinga", Cuadernos de Vivienda y Urbanismo No.2, INJAVIU, Universidad Javeriana (2009). 
En este sentido, el concepto de ciudades gemelas no sólo se refiere a partes idénticas u objetos similares, sino también a las diferentes interacciones y conexiones con el territorio de acuerdo a cómo se ha generado el desarrollo urbano a cada lado de la frontera y, por consiguiente, para que estos aspectos puedan ser clasificados como simétricos y asimétricos se tiene como punto de "quiebre" el límite internacional.

\subsection{Leticia y Tabatinga vistas como ciudades gemelas en el marco del concepto de frontera}

A lo largo de la frontera colombiana en la región amazónica, el caso de Leticia (Colombia) y Tabatinga (Brasil) es el más sobresaliente en cuanto a ciudades transfronterizas o gemelas, porque son las ciudades de mayor población y tamaño, de igual jerarquía político administrativa al ser municipios y, en donde, además de contar con la presencia de instituciones y entidades del gobierno central ya se encuentran conurbadas.

Adicional a su carácter "insular", debido a que la accesibilidad a las dos ciudades se realiza por transporte aéreo o fluvial, su origen también se debe a su condición fronteriza: i) Tabatinga fue fundada como un asentamiento militar en 1776 por los portugueses para controlar la movilidad en el Río Amazonas y como "portal" de ingreso al "Imperio Portugués" (Steinman, 2005); mientras que, ii) Leticia se fundó en 1867 con la idea de hacer presencia en el territorio fronterizo frente a Tabatinga. Hoy en día ambas ciudades cuentan con gobiernos locales como resultado del proceso de descentralización de los dos países, así mismo, en ambas áreas urbanas se encuentran sedes de universidades e instituciones del nivel nacional y/o federal, regional y local. En cuanto a la población, ambas ciudades presentan aproximadamente el mismo tamaño debido a que Tabatinga cuenta con 26.539 habitantes, mientras Leticia tiene 27.760 habitantes (IBGE, 2002, DANE, 2005). Igualmente, el proceso de crecimiento urbano de las ciudades se desarrolló hacia el límite internacional, hasta generar su conexión física tanto a nivel vehicular como a través de la "franja de frontera" entre barrios vecinos, en donde los habitantes circulan sin ningún tipo de restricción; adicionalmente, ambas ciudades se comunican por medio fluvial precisamente a través del Río Amazonas.

De otra parte, Leticia y Tabatinga entendidas como una sola área urbana (aglomeración resultado de la conurbación), conforman un espacio que es fruto de las interacciones sociales de los habitantes fronterizos. Dicho espacio se constituye en la franja que une a las ciudades, en términos de Machado el límite, en vez de separar, se constituye en un espacio socialmente construido (Machado, 1998). Por consiguiente, el límite fronterizo considerado como una línea de borde y separación, se diluye para transformarse en un espacio en donde tienen lugar flujos e interacciones entre sus habitantes. Desde las ciencias sociales, disciplinas como la geografía humana plantean que la frontera como concepto no debe ser vista como un límite o una línea sino, más bien, como parte de una construcción social del espacio a través del establecimiento de dominios y delimitaciones por parte de los habitantes fronterizos; por lo tanto, se considera que la frontera tiene un papel articulador que separa y conecta al mismo tiempo ${ }^{10}$ 
El caso de las ciudades de Leticia y Tabatinga, se constituye en un claro ejemplo de ciudades gemelas que en términos simétricos tales como su tamaño, población, actividades transfronterizas, instituciones de similar jerarquía, gobiernos locales, localización periférica con respecto a las ciudades capitales de su respectivo país, e incluso en cuanto al origen de su fundación. Este último permite afirmar que Leticia y Tabatinga se constituyen en el punto de encuentro entre el patrón de asentamiento urbano español y portugués. Adicionalmente, hoy en día, las ciudades de Leticia y Tabatinga conforman sub-espacios socialmente construidos a través de flujos transfronterizos, como se explica más adelante, que plantean tanto escenarios de cooperación en el plano del intercambio comercial, como de competencia en términos de oferta de bienes y servicios, oportunidades de estudio y trabajo, servicios de transporte fluvial; no obstante, ambas áreas urbanas también enfrentan problemas comunes tales como la migración de población, conformación de asentamientos precarios y contaminación del medio ambiente urbano.

Actualmente, se afirma a nivel local que Leticia tiene el liderazgo en la región denominada "triple frontera" entre Colombia, Brasil y Perú, la cual tiene un radio de influencia de aproximadamente $150 \mathrm{~km}$. dentro del cual se localizan Leticia y Puerto Nariño (Colombia) con 30.000 habitantes, Tabatinga y Benjamín Constant (Brasil) con 49.000 habitantes y Caballo Cocha (Perú) con 10.000 habitantes. Como respuesta a la conformación de esta sub-región, el Gobierno Federal del Brasil ha incrementado las inversiones y recursos, específicamente en educación e infraestructura, en las ciudades de Tabatinga y Benjamín Constant con el propósito de convertirlas en epicentros regionales (SINCHI, 2004).

\subsection{Cooperación transfronteriza}

La cooperación transfronteriza se ha constituido, hoy en día, en un nuevo aspecto a tratar entre países para encontrar maneras que permitan un adecuado manejo de las dinámicas que se presentan a lo largo de los límites internacionales, especialmente aquellos aspectos generados en los territorios fronterizos en donde se localizan áreas urbanas y conurbaciones transfronterizas. En el mundo contemporáneo las ciudades fronterizas juegan un papel muy importante como punto de encuentro para el comercio y la economía de mercado mundial. En este contexto, la cooperación transfronteriza ha sido parte de la agenda nacional entre distintos países vecinos, en aspectos tales como el medio ambiente, la infraestructura, las migraciones y recientemente la seguridad", los cuales se manifiestan con mayor fuerza en las áreas urbanas o ciudades localizadas a lo largo de las fronteras, constituyéndose el medio ambiente construido en un escenario importante de cooperación. La cooperación transfronteriza entre países puede perfeccionarse en tres niveles: i) Estados-nación, ii) gobiernos regionales y/o departamentales, $y$ iii) gobiernos locales ${ }^{\prime 2}$.

Uno de los procesos más recientes de cooperación transfronteriza a nivel nacional, regional y local es precisamente la Unión Europea, la cual se sustenta en la idea de integración a través de una misma visión de futuro entre los miembros de la Unión. En términos de cooperación, la Unión Europea ha manifestado en varios documentos de política la importancia de generar redes entre los Estados
10 Vargas López de Mesa, 2004, Fronteras: espacios conceptuales y materiales en el contexto de la y materiales en el contexto de la Metáforas, Instituto de Estudios Regionales, INER, Universidad de Antioquia., Colombia.

II Los Estados Unidos y España han enfrentado las dificultades de manejar lo los flujos de personas que intentan entra a sus territorios ilegalmente.

12 Los acuerdos internacionales entre Estados-nación han sido un aspecto importante en las relaciones internacionales durante el siglo $\mathrm{XX}$ en aspectos como los derechos humanos (ej UN 1948), medio (ej. UN 1948), medio ambiente (Ej. Protocolo de Kyoto), la integración (E. Unión Europea) y recientemente en el intercambio comercial (ej. NAFTA Mercosur - CAN), y seguridad (Ej. US national security policy). 
13 Church, A., Reid, P., 1996, Urban Power, International Networks and Competition The Example of Cross-border Cooperation Urban Studies, Vol. 33, No. 8, $1297 \pm$ 1318.

14 Goodno, J.B., Aug/Sep 2003 Hands across the border, Planning, Vol.69, Iss. 8; p. 20, Chicago, USA

15 Para ver una descripción más detallada del estudio de caso de ambas ciudades y los barrios objeto de estudio: Vergel, E., "Ciudades Gemelas en Fronteras Amazónicas: Estudio de Caso Leticia y Tabatinga", Cuadernos de Vivienda $y$ Urbanismo No. 2, INIAVIU, Universidad Urbanismo $200.2,1 \mathrm{NJAVIU}$, Universidad Javeriana (2009). miembro y sus regiones, marco en el cual algunos gobiernos locales han avanzado en este sentido a través del establecimiento de las euro-ciudades región (eurocity regions) (Church, Raid, 1996) ${ }^{13}$.

Con respecto al tercer nivel, es decir, el nivel local, la cooperación transfronteriza es una herramienta importante para los gobiernos municipales de ciudades fronterizas en cuanto a la posibilidad de brindar mejores servicios a su población, facilitar las comunicaciones, el transporte urbano y regional, en la articulación para el manejo de recursos naturales (ej. fuentes del recurso hídrico), así como en acuerdos comerciales y manejo de procesos migratorios, entre otros. Lo anterior es aún más factible en países con procesos de descentralización impulsados desde el gobierno central. Tal es el caso de las iniciativas de cooperación transfronteriza que se han plateado en la frontera entre México y Estados Unidos en donde planificadores y representantes de gobiernos locales de ciudades gemelas (ej. San Diego-Tijuana, El Paso-Ciudad Juárez) han acordado trabajar en temas como el transporte y el manejo de aguas residuales ${ }^{14}$.

\section{ESTUDIOS DE CASO ${ }^{15}$, HALLAZGOS Y ANÁLISIS}

A continuación se presenta una breve descripción del área objeto de estudio, la Quebrada San Antonio en el límite fronterizo entre las ciudades de Leticia (Colombia) y Tabatinga (Brasil), posteriormente, una descripción de la arquitectura desarrollada por los habitantes del área objeto de estudio en los barrios La Unión (Leticia) y Tabatinga (Brasil).

\section{I La Quebrada San Antonio como el área objeto de estudio en la franja de frontera}

La Quebrada San Antonio se constituye en la frontera natural y políticoadministrativa entre Colombia y Brasil a partir del punto de encuentro vehicular entre ambas ciudades hasta el Río Amazonas. La quebrada es una microcuenca tributaria del Río Amazonas que antes de desembocar en el Río, genera una pequeña montaña en territorio brasileño (Tabatinga). La Quebrada San Antonio ha sido utilizada por Leticia como uno de los lugares para la disposición final del alcantarillado de la ciudad sin ningún tipo de tratamiento, lo cual ha deteriorado la calidad del medio ambiente en ambas ciudades así como del Río Amazonas. Esta situación se ha convertido en un problema binacional debido a los altos niveles de contaminación que genera la Quebrada San Antonio sobre el Río Amazonas, al constituirse éste último en una de las fuentes del recurso hídrico para el sistema de acueducto de la ciudad de Tabatinga.

Otro aspecto importante en este espacio de la Quebrada es el proceso de ocupación por parte de población de origen peruano, brasilero y colombiano en los barrios de La Unión (Leticia) y Guadalupe (Tabatinga). Principalmente por su condición periférica en términos limítrofes, los barrios localizados en la Quebrada San Antonio son un espacio propicio para la conformación de actividades 
informales que al no contar con algún control por parte de los gobiernos locales, se constituye en otro problema común transfronterizo.

El espacio de la Quebrada San Antonio ha sido ocupado por los asentamientos precarios de La Unión (Leticia) y Guadalupe (Tabatinga) en ambos lados del límite fronterizo con implicaciones sin precedentes en las ciudades gemelas. Primero, la degradación ambiental ha alcanzado altos niveles de contaminación por la disposición final del alcantarillado que realiza la ciudad de Leticia, así como la disposición final del asentamiento La Unión que no cuenta con saneamiento básico; por lo anterior, las condiciones de salubridad de la población en el barrio La Unión son críticas, especialmente en la población infantil. El crecimiento del barrio La Unión durante las últimas dos décadas ha llevado a la ocupación de una parte del territorio brasileño al otro lado de la Quebrada. Adicionalmente, durante los periodos de inundación por la creciente del Río Amazonas, tanto La Unión como Guadalupe se inundan y generan condiciones de riesgo para la población.

Mapa 6. Área Objeto de Estudio: Localización de los barrios La Unión (Leticia) y Guadalupe (Tabatinga).

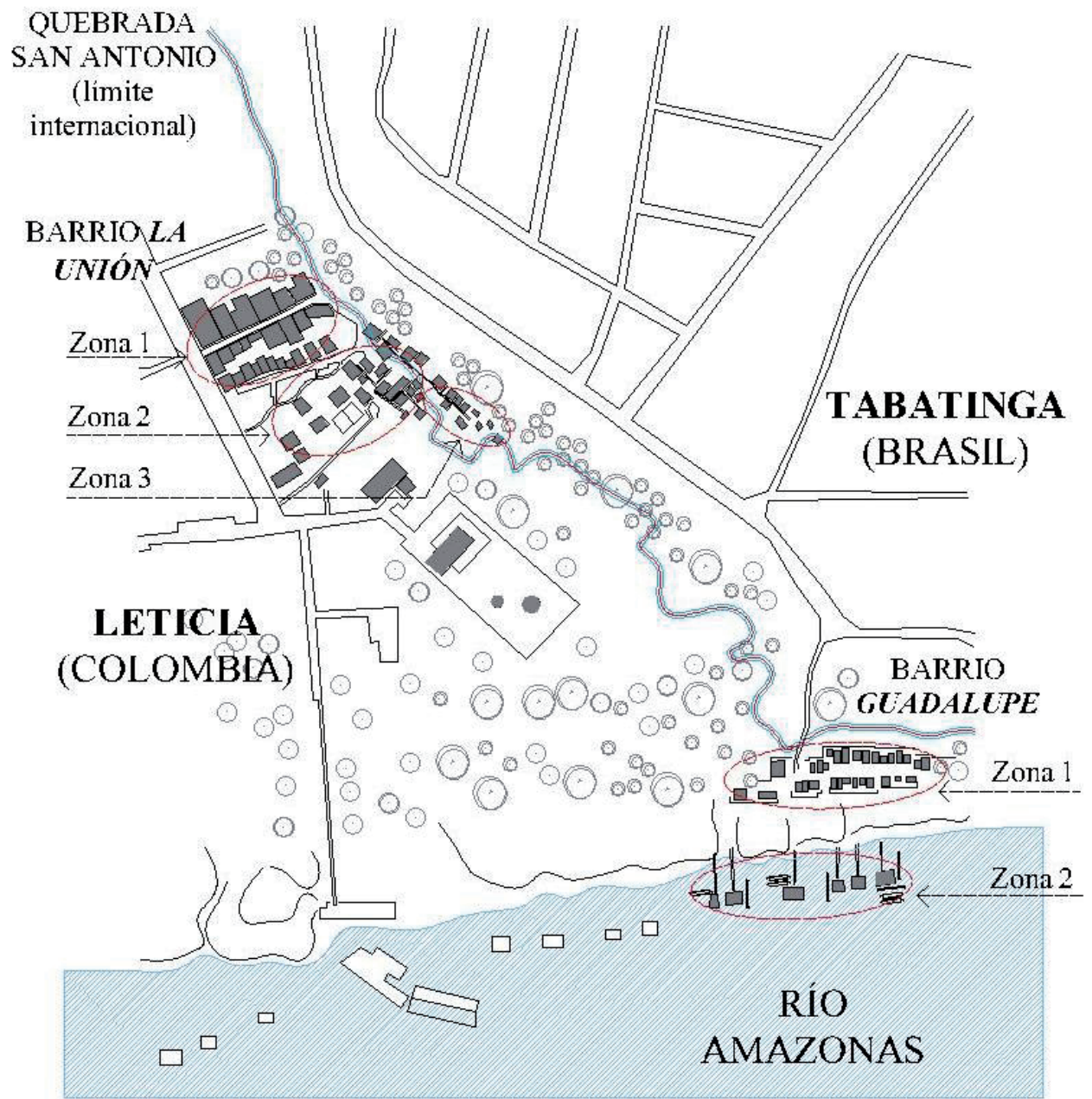

Fuente: Elaboración propia (2006). 


\subsection{Unidades de análisis y arquitectura desarrollada por sus habitantes}

\subsection{Barrio La Unión}

El barrio La Unión se divide en tres áreas en concordancia con su proceso de crecimiento y consolidación. Justo al frente del barrio El Castañal se encuentran localizadas un grupo de viviendas que comenzaron el proceso de urbanización con un patrón de asentamiento lineal. Doña Raimunda, brasilera de nacimiento, líder comunitaria del barrio, madre de 8 hijos y casada con Don Wilson, ciudadano colombiano, y con más de 20 años vividos en el barrio comenta: "eran sólo 3 casas en la manzana, y la Quebrada era hermosa, incluso nosotros podíamos tomar agua limpia de ella. Nosotros hemos vivido en tres casas diferentes en el barrio; ya vendimos la primera y la segunda casa, y para nuestra primera casa nosotros conseguimos el lote con un amigo" 16 .

Entrevista con Doña Raimunda duran el trabajo de campo en Leticia, Julio de 2006.

De esta forma, el barrio se subdivide en tres zonas de acuerdo con su proceso de crecimiento. La Zona I corresponde al sector más consolidado en términos de contar con viviendas en "material", es decir en ladrillo y cemento y en algunos
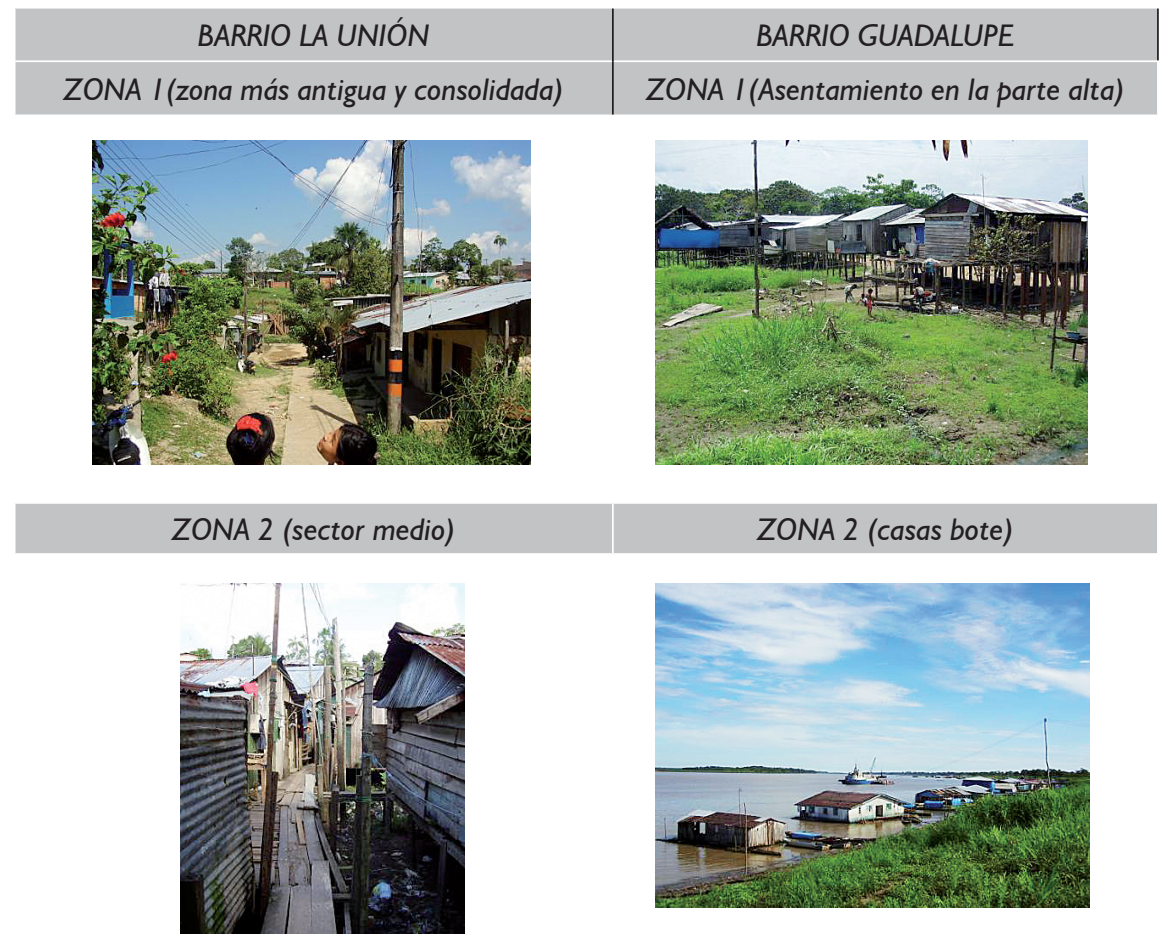

ZONA 3 (zona más baja y desarrollo más reciente)

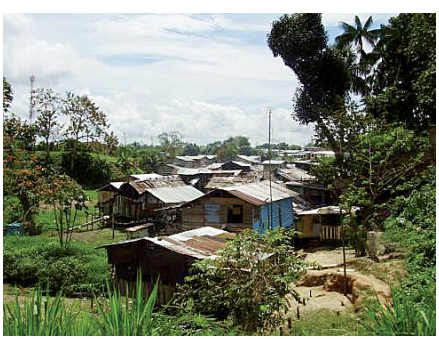

Fuente: El autor, trabajo de campo (2006) 
casos con dos pisos, éste es el sector en el que doña Raimunda y su familia viven. La Zona 2 corresponde al crecimiento del barrio hacia la quebrada San Antonio sin un patrón de asentamiento definido en donde las viviendas presentan estructuras palafíticas y se intercomunican a través de puentes de madera. La zona 3 es la reciente ocupación de la parte más baja de la Quebrada, junto a la Planta Eléctrica de Leticia, así como la reciente ocupación de territorio brasileño. En cuanto al uso de la vivienda, se encontró que el $91 \%$ de ellas son utilizadas sólo como dormitorio, mientras que el $8,3 \%$ cuenta con una actividad económica generadora de ingresos, dentro de este grupo, $71 \%$ de las viviendas cuentan con una tienda y $14 \%$ arriendan habitaciones. Para el $42 \%$ de las unidades de vivienda visitadas, estas actividades económicas representan el principal ingreso de los hogares.

\subsection{Barrio Guadalupe}

El barrio es el resultado de un proceso de crecimiento lineal en dos periodos básicamente. De acuerdo con lo que la primera persona en asentarse en esta área en 1988 comenta: "Yo decidí organizar el barrio en una línea de casas porque el agua del Río Amazonas estaría frente de estas casas, y es lo que siempre hacemos en las comunidades de dónde venimos. Hoy en día, el borde del Río cambió, entonces nosotros organizamos una segunda línea de viviendas frente a las primeras"17. Igualmente, existen algunas "casas bote" que flotan en el Río Amazonas y se encuentran ancladas a ciertos árboles o postes de madera, Estas "casa bote" brindan facilidades para los servicios de transporte fluvial desde Tabatinga hacia Leticia (Colombia) y Santa Rosa (Perú). En cuanto al uso de la vivienda, se encontró que el $62 \%$ son utilizadas sólo como dormitorio, y el $37 \%$ de ellas cuenta con una actividad económica en su interior, dentro de éste último grupo, $85 \%$ de las viviendas cuentan con la elaboración de artesanías y la venta de comida como las actividades económicas, y $14 \%$ una tienda.

\subsection{Percepciones de la frontera por parte de los habitantes}

\subsection{Cruces transfronterizos}

Durante las visitas a las unidades de vivienda en el barrio La Unión fue posible preguntar a sus habitantes acerca de su percepción sobre el límite fronterizo y la condición de vivir en la frontera. Cuando se les preguntó qué tan seguido ellos cruzan la frontera entre Leticia y Tabatinga, 39\% mencionaron todos los días, $30 \%$ dijeron frecuentemente, $17 \%$ algunas veces, mientras que el $9 \%$ mencionaron que nunca cruzan la frontera. Además, al interior del grupo que cruza la frontera, 57\% mencionaron que la cruzan para realizar compras, $21 \%$ por motivos de trabajo, $5 \%$ por otras razones y $2,3 \%$ por motivos de estudios.

En el Barrio Guadalupe cuando los habitantes fueron preguntados acerca de que tan seguido cruzan la frontera entre Leticia y Tabatinga, $29 \%$ respondieron todos los días, $18 \%$ dijeron frecuentemente, $29 \%$ algunas veces, mientras que
17 Entrevista con la líder indígena Co- cama quien organizó el asentamiento y todavía vive en el barrio. Trabajo de campo en Tabatinga, Julio de 2006.


$18 \%$ dijeron nunca cruzar la frontera. Además, al interior del grupo que cruza la frontera, $70 \%$ mencionaron que la cruzan para realizar compras, $2 \%$ por motivos de trabajo, $10,8 \%$ por motivos de estudio y $5 \%$ por otras razones.

Gráficos I y 2. Cruces transfronterizos y frecuencia

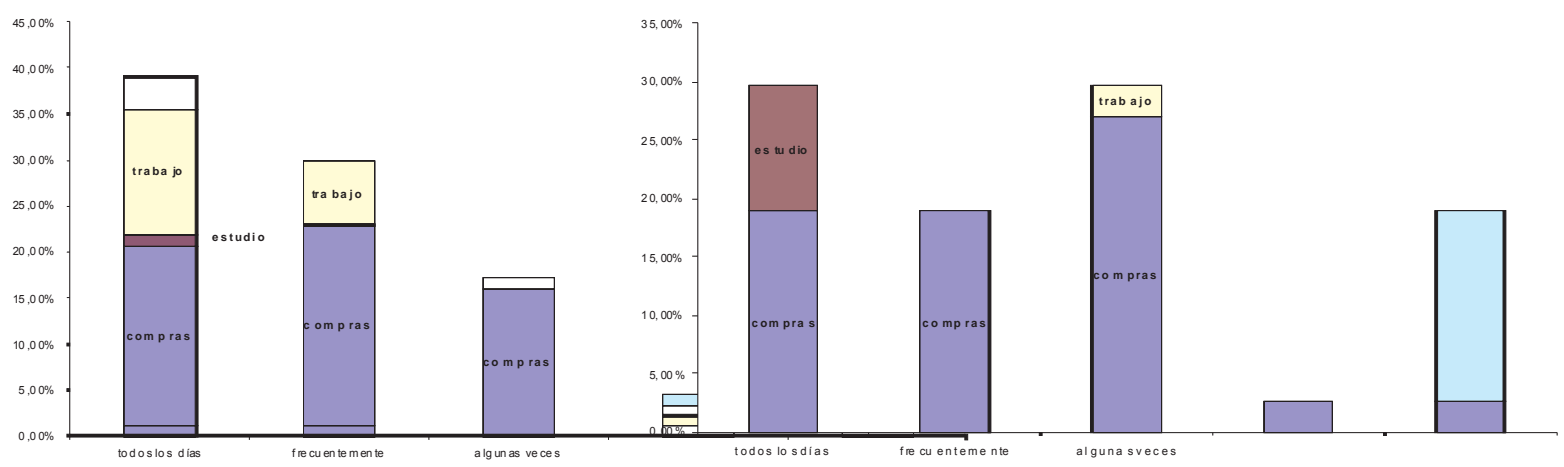

Fuente: El autor, trabajo de campo (2006)

\subsubsection{Lazos familiares y servicios transfronterizos}

En el Barrio La Unión, acerca de contar con lazos familiares transfronterizos, $60 \%$ de los entrevistados mencionaron contar con familiares en la ciudad vecina, mientras que el $37 \%$ restante dijeron no tenerlos, y el $89 \%$ de las personas dijeron no tener ningún tipo de propiedad en la ciudad vecina mientras que $2,30 \%$ respondieron tenerla. Con respecto a contar con servicios públicos de la ciudad vecina (Tabatinga), 59\% mencionaron no recibir ningún servicio transfronterizo; no obstante, los siguientes grupos de personas mencionaron recibir los siguientes servicios de la ciudad vecina: $20 \%$ reciben servicios de salud y educación, I7\% únicamente servicios de salud y $2,30 \%$ electricidad.

Gráficos 3 y 4 . Servicios transfronterizos

Barrio La Unión (Colombia)

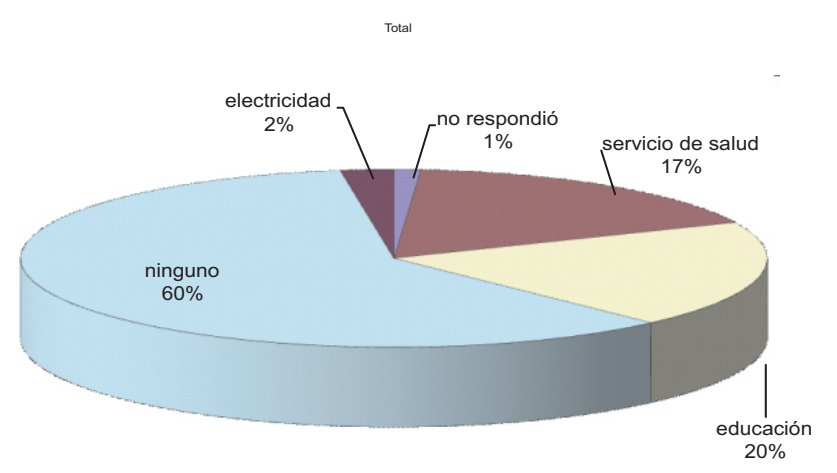

Barrio Guadalupe (Brasil)

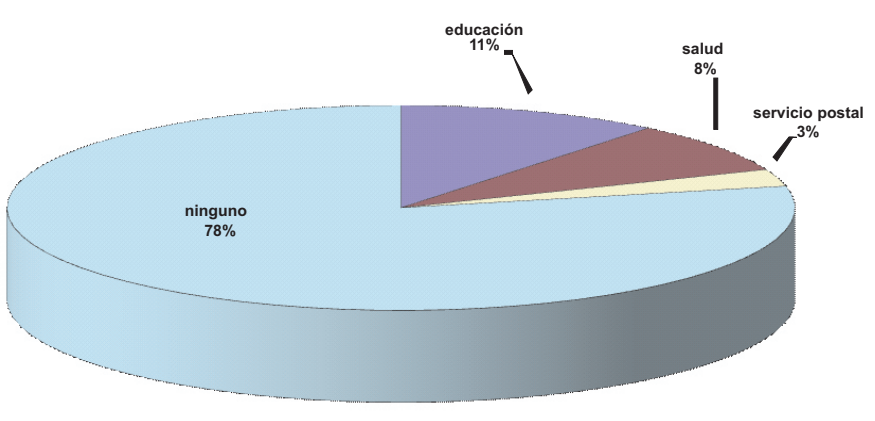

Fuente: El autor, trabajo de campo (2006) 
De otra parte, se les preguntó a los habitantes del Barrio La Unión acerca de si tenían intenciones de mudarse a la ciudad vecina o de solicitar apoyo a las autoridades del otro país. El $73 \%$ contestó que no tiene intenciones de solicitar apoyo al otro lado de la frontera, mientras que $20 \%$ dijeron haberlo pensado. El $64 \%$ contestó que no tiene planes de mudarse a la ciudad vecina (Tabatinga), mientras que el $34 \%$ contestó haberlo pensado algunas veces. Finalmente, el $93 \%$ de las personas entrevistadas (cabezas de hogar) respondieron SI cuando fueron preguntados si las dos ciudades deberían trabajar conjuntamente para mejorar las condiciones de vida del barrio.

En el Barrio Guadalupe, acerca de contar con lazos familiares transfronterizos, $55 \%$ de los entrevistados mencionaron contar con familiares en la ciudad vecina, mientras que el $45 \%$ restante dijeron no tenerlos. El $97 \%$ de las personas dijeron no tener ningún tipo de propiedad en la ciudad vecina mientras que $2,70 \%$ respondieron tenerla. Con respecto a contar con servicios públicos de la ciudad vecina (Leticia), 78\% mencionaron no recibir ningún servicio transfronterizo; no obstante, los siguientes grupos de personas mencionaron recibir los siguientes servicios de la ciudad vecina: $8,11 \%$ reciben servicios de salud y educación, $10,8 \%$ únicamente servicios de educación y $2,70 \%$ servicio de correo.

De otra parte, se les preguntó a los habitantes del Barrio Guadalupe acerca de si tenían intenciones de mudarse a la ciudad vecina o de solicitar apoyo a las autoridades del otro país. El $94 \%$ contestó que no tiene intenciones de solicitar apoyo al otro lado de la frontera, mientras que $5 \%$ dijeron haberlo pensado. El $86 \%$ contestó que no tiene planes de mudarse a la ciudad vecina, mientras que el $13 \%$ contestó haberlo pensado algunas veces. Finalmente, el $94 \%$ de las personas entrevistadas (cabeza de hogar) respondieron SI cuando fueron preguntados si las dos ciudades deberían trabajar conjuntamente para mejorar las condiciones de vida del barrio.

\section{CONCLUSIONES}

\section{I Ciudades gemelas y fronteras}

El artículo muestra la relevancia de llevar a cabo estudios fronterizos para comprender la concentración de las dinámicas transfronterizas que tienen lugar en el medio ambiente construido, específicamente aquellas relacionadas con la concentración de redes, flujos y procesos que se generan en estos puntos de intercambio. Así mismo, es importante resaltar que una aproximación al concepto de ciudades gemelas no sólo debe radicar en la similitud entre ambos lados del límite fronterizo, sino en la identificación de aquellos aspectos simétricos y asimétricos que caracterizan cada una de las áreas urbanas y sus respectivas relaciones transfronterizas.

Así mismo, cabe destacar que en la medida en que el territorio puede estar delimitado por un límite internacional, las fronteras no pueden verse como línea, sino más bien como un espacio que une y separa al mismo tiempo. El espacio fronterizo puede generar franjas más amplias o esbeltas de acuerdo a las dinámicas que se generen; no obstante, es precisamente en ciudades fronterizas en donde 
dicho espacio toma mayor relevancia debido a que su construcción se debe a la interacción de los habitantes con su territorio.

En este contexto, la cooperación transfronteriza entre ciudades gemelas para el manejo de dinámicas y problemas comunes en las franjas de frontera, deben propender por trabajar conjuntamente en aquellos aspectos simétricos, mientras que a través de la identificación de aspectos asimétricos cada ciudad podrá aprender de los procesos que se generan en la otra. Lo anterior, plantea que las ciudades gemelas se ven enfrentadas a definir si hacia el futuro buscarán potencializar aquellos aspectos asimétricos hacia un escenario de competencia con su contraparte, o por el contrario dichos aspectos deben prevenir futuros desarrollos o plantear escenarios de cooperación. Este es un dilema al que se ven enfrentadas las ciudades gemelas, sus gobiernos y habitantes frente a aquellos aspectos considerados asimétricos.

\subsection{Metodología de investigación para estudios fronterizos}

La metodología de investigación desarrollada en el estudio plantea en primer lugar que para poder comprender de manera integral los procesos que se generan en territorios fronterizos, es necesario definir un área objeto de estudio que contenga unidades de análisis comparables a cada lado de la frontera. Basados en la definición de variables y aspectos relacionados con el tema de investigación, es posible proceder con la identificación de aspectos simétricos y asimétricos, los cuales se constituyen en un insumo clave tanto para caracterizar, definir y comprender dinámicas en ciudades gemelas, como para la formulación de propuestas y escenarios para el futuro en el manejo de los mismos. En esta medida, la identificación de los aspectos simétricos permite definir escenarios de cooperación, especialmente aquellos relacionados con problemas compartidos, mientras que la identificación de los aspectos asimétricos plantea un reto mayor para las ciudades gemelas porque ponen en evidencia en qué temas podrían competir. Tal vez, una ciudad pueda atraer más población altamente calificada al ofrecer mejores salarios o ventajas comparativas en términos tributarios, acceso a vivienda, bienes y servicios.

De otra parte, si bien la metodología de investigación se llevó a cabo en relación al fenómeno de asentamientos precarios en ciudades gemelas, ésta no sólo se circunscribe a estudios de arquitectura y urbanismo, sino también a otras áreas del conocimiento que pretendan comprender las dinámicas transfronterizas que tienen lugar en ciudades gemelas, que al basarse en una aproximación conceptual espacial de las ciudades fronterizas y su condición, permite ser utilizada en otros campos del conocimiento.

\subsection{Arquitectura amazónica como insumo para proyectos de vivienda de interés social VIS}

Dado que los asentamientos estudiados están conformados por grupos de bajos ingresos de las ciudades gemelas de Leticia y Tabatinga, y que la formación de este tipo de barrios se debe precisamente al creciente déficit habitacional sumado a la 
baja oferta de suelo y vivienda en esta conurbación, es importante destacar que las tipologías de vivienda brindan insumos claves para la reactivación de dicha oferta. En este sentido, se concluye que para lograr proyectos de vivienda de interés social VIS acordes con las realidades locales, es necesario incorporar aspectos que faciliten la producción de vivienda por parte de los mismos habitantes a través de procesos como la autoconstrucción que permitan un crecimiento progresivo. Entre los dos asentamientos analizados se destaca la tipología de Vivienda I del barrio Guadalupe, la cual genera arquitectura palafítica a partir de una plataforma en madera cuadrada como primera fase, y que posteriormente crece hacia atrás para generar espacios para la cocina, ropas y alcobas, e incluso áreas de cultivo en la parte posterior del terreno. Lo anterior plantea la importancia de generar oferta de lotes con urbanismo de mayor profundidad en las ciudades gemelas que permitan un desarrollo en el tiempo por parte de los habitantes. Así mismo, se destacan las actividades generadores de ingreso que se desarrollan por parte de los habitantes de manera informal, y que las propuestas de VIS en ambas ciudades deberían considerar.

En relación con el patrón de asentamiento, es evidente que la Zona I del Barrio la Unión y todo el Barrio Guadalupe plantean una ocupación del suelo a través de un esquema lineal. Este patrón de asentamiento además de mostrar un eficiente uso del suelo, la posibilidad de crecimiento progresivo de las viviendas y la flexibilidad para el desarrollo de diferentes unidades habitacionales, se constituye en un importante insumo para el diseño urbano de proyectos de vivienda formal. Por consiguiente, se recomienda que las propuestas de diseño urbano para nuevos desarrollos habitacionales en las ciudades gemelas deberían considerar este tipo de patrones de asentamiento que facilitan la realización de obras de urbanismo, el crecimiento por fases y la organización espacial de tipologías de viviendas producto de materiales de la región.

\subsection{Percepciones acerca de la frontera}

Resulta de gran interés encontrar que para los habitantes de los barrios analizados en algunos casos fue difícil responder la pregunta acerca de cuántas veces cruza la frontera debido a que no perciben el límite internacional como tal. No obstante, las personas cabeza de hogar perciben la frontera en la medida que consideran que se desplazan a la otra ciudad por razones de trabajo, estudio o servicios de salud. Éstos se constituyen en flujos y servicios transfronterizos los cuales se convierten en una de las razones de mayor peso para asentarse en el barrio ${ }^{18}$. Precisamente la Quebrada San Antonio al ser el espacio que separa como límite internacional a las dos ciudades es, a su vez, el espacio que integra a través de estos dos barrios a la conurbación, especialmente porque las ciudades gemelas al ser vistas como un todo, estos barrios dejan de ser periféricos para constituirse en el centro de ambas. De esta forma La Quebrada de San Antonio se constituye en un espacio de intercambio en donde el límite internacional se diluye cuando la población recibe servicios públicos, de salud y/o de educación de parte de la ciudad vecina sin ningún tipo de restricción. Lo anterior plantea que los problemas generados por el asentamiento de población en la Quebrada San Antonio se convierten en un problema común de las ciudades gemelas $y$, por consiguiente, la percepción por parte de los habitantes frente a una acción conjunta de los gobiernos locales de ambas ciudades para mejorar sus condiciones de vida es positiva.
18 Ver razones para asentarse en el barrio en Vergel, E. "Ciudades Gemelas en Fronteras Amazónicas: Estudio de Caso Leticia y Tabatinga", Cuadernos de Vivienda y Urbanismo No. 2, INJAVIU, Universidad Javeriana (2009). 


\section{IMPLICACIONES DE LA INVESTIGACIÓN}

La investigación se ha constituido en insumo y punto de partida en la formulación de políticas, programas y proyectos en los cuales se ha visto involucrado el autor.

Primero, el autor ha estado involucrado en el proceso de actualización del Macroproyecto La Yesca en el Municipio de Quibdó, el cual tiene como objetivo implementar una actuación urbana integral para mejorar las condiciones de vida de la población asentada a lo largo de la Quebrada La Yesca en este municipio, capital del Departamento del Chocó. La investigación se constituyó en insumo del Documento "Fase Cero" que el autor desarrolló como parte de sus actividades en el Departamento Nacional de Planeación DNP. Básicamente las recomendaciones del estudio permitieron establecer la manera apropiada de aproximarse al fenómeno de ocupación de una quebrada, en este caso de mayor escala, así como identificar las fases necesarias para actualizar, reformular e implementar el Macroproyecto en el municipio de Quibdó, teniendo en cuenta recomendaciones de la investigación tales como: adelantar un estudio de amenazas y riesgos, desarrollar procesos de abajo hacia arriba teniendo en cuenta las características socioeconómicas de la población, y con base en los estudios desarrollados, actualizar los instrumentos de planificación como el Plan de Ordenamiento Territorial POT.

Segundo, el autor estuvo involucrado en la formulación del Documento CONPES 3604 "Lineamientos para la consolidación de la política de mejoramiento integral de barrios MIB", el cual establece como uno de los sus objetivos específicos: "mejorar el conocimiento de las condiciones de riesgo en los asentamientos precarios como insumo para adelantar programas y proyectos de MIB". Esto se debe precisamente a la necesidad de contar con mayor información acerca de las condiciones de riesgo en que habita la población en asentamientos precarios, como lo plantea la investigación en sus conclusiones y recomendaciones para el caso específico de Leticia, situación que también se presenta en otros municipios del país.

Tercero, durante los meses de junio y julio de 2008, el autor tuvo la oportunidad de tomar un curso internacional de desarrollo urbano en la ciudad de Tokio (Japón), ciudad en la cual tuvo casualmente la oportunidad de conocer a un estudiante colombiano que adelantaba en ese entonces sus estudios de pregrado en arquitectura y paisajismo en la Universidad de Chiba, en la ciudad de Tokio (Japón). Este estudiante le comentó al autor su interés de trabajar la ciudad de Leticia para su tesis de pregrado en el Department of Environmental Sciences \& Landscape Architecture. A partir de este encuentro casual en la ciudad de Tokio, el estudiante de pregrado en arquitectura y paisajismo desarrolló sus tesis "Leticia's waterfront: an amazonian challenge for flood prone area's planning and design", la cual tuvo como objetivo: i) identificar los factores sociales y ambientales que afectan la planeación y diseño de zonas inundables en Latinoamérica y la Amazonía, ii) analizar los problemas y las oportunidades que el frente fluvial de Leticia enfrenta, y las necesidades locales, deseos y expectativas de la población, y, iii) desarrollar una propuesta alternativa para el frente fluvial de Leticia, reconectar la ciudad con el río así como responder a las necesidades locales (Uribe, J.C., 2009). De esta forma, la investigación brindó un punto más de partida para una nueva tesis que analizará la ciudad de Leticia, al generar procesos de construcción de conocimiento. 
Finalmente, las implicaciones del estudio plantean un mensaje para los estudiantes de arquitectura. La importancia de aquellos interrogantes que surgen a través tanto del proceso de formación en las escuelas de arquitectura como en el ejercicio de la profesión, estas preguntas son el principal insumo tanto para desarrollar trabajos de investigación como para comprender la realidad de nuestras ciudades. Así mismo, los resultados y productos de estos procesos de investigación deben propender por aportar tanto a la construcción del conocimiento, como aportar propuestas que permitan mejorar el proceso de mejoramiento del medio ambiente construido, su planificación de acuerdo a las personas que lo habitan, y también el desarrollo de proyectos de arquitectura acordes con las realidades locales. De esta forma podremos aportar desde nuestra disciplina a mejorar nuestras ciudades y construirlas más sostenibles en y para el futuro.

\section{BIBLIOGRAFÍA}

Becker, B. (1995). Undoing Myths: The Amazon - an urbanized forest. Man and Biosphere Series, Vol. 15 UNESCO

Browder, J.O. \& Godfrey, Brian, J. (1997). Rainforest Cities, Urbanization, Development, and Globalization of the Brazilian Amazon. Columbia University Press

Church, A., Reid, P. (1996). Urban Power, International Networks and Competition: The

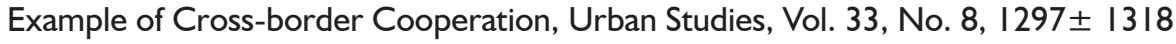

Congreso Nacional de Colombia, (1997). Ley 388 de Desarrollo Territorial

Congreso Nacional de Brasil (200I). Estatuto da Cidade, Ley 10.257 del 10 de Julio de 2001

CONPES, Consejo Nacional de Política Económica y Social, (2004), Documento No. 3305 "Lineamientos para Optimizar la Política de Desarrollo Urbano"

CONPES, Consejo Nacional de Política Económica y Social, (2009), Documento No. 3604 "Lineamientos para la consolidación de la política de mejoramiento integral de barrios MIB"

Departamento Nacional de Planeación DNP (2008), Documento Fase Cero, Macroproyecto Quebrada La Yesca, Municipio de Quibdó, Departamento del Chocó

Ehlers, N., Buursink, J., Boekema, F. (200I). Introduction: Binational cities and their regions: From diverging cases to a common research agenda. GeoJournal, 54: I - 5

Goodno, J.B. (Aug/Sep 2003). Hands across the border, Planning, Vol.69, Iss. 8; p. 20, Chicago, USA

Giraldo Isaza, F. (1999). Ciudad y Crisis, Tercer Mundo Editores 
Grisales, G. (2005). ¿Does the Colombia, Brazil and Peru common borderland needs an integration border regime? Aldea Mundo • Revista sobre Fronteras e Integración. Año 10, No. 18 / Mayo $2005 \cdot$ ISNN I316-6727

Gutiérrez Rey, F., Acosta Muñoz, L.E., Salazar Cardona, C.A. (2003). Perfiles Urbanos en la Amazonía Colombiana: un enfoque para el desarrollo sostenible, Instituto Amazónico de Investigaciones Científicas, SINCHI

. (2003). La Amazonía Colombiana, II Workshop, Relações Campo-Cidade e Identidades Regionais nas Amazônias: Tendências do Desenvolvimento e Opções Políticas numa Perspectiva Comparativa.

Hurtado Gómez, L.M. (2004). Pobreza y Marginalidad Urbanas en la Amazonía. Un estudio de caso de los asentamientos ubicados en zonas inundables, Tesis de Maestría en Estudios Amazónicos, Universidad Nacional de Colombia, Sede Leticia.

Machado, L.O. (1998). Limites, Fronteiras, Redes, Fronteiras e Espaco Global, AGB-Porto Alegre, Porto-Alegre, p.4I-49

Ministerio de Ambiente Vivienda y Desarrollo Territorial (2005). Guía Metodológica I. Incorporación de la Prevención y la Reducción de Riesgos en los Procesos de Ordenamiento Territorial. Serie Ambiente y Ordenamiento Territorial.

Ministerio de las Ciudades (200I). Plano Diretor Participativo, Guia para a Elaboracao pelos Municipios e Cidadaos, Brazil.

Ministerio de Integración, Gobierno Federal (2006). Restructured Development Program of Border's Fringe, Twin Cities Strategy Actions, Brazil.

Municipio de Leticia (2002). Plan de Ordenamiento Territorial PBOT de Leticia. Concejo Municipal de Leticia, Amazonas, Colombia.

Navarro, Rachelle G. (1994). Improving sanitation in coastal communities with special reference to Puerto Princesa, Palawan Province, Philippines, Msc. Thesis, Mc Gill University, Canada

Peña, Sergio, Cross-border Planning, What is it? Implications for the U.S.-Mexico Border

Programa Calha Norte, Prefeitura de Tabatinga, Fundación Getulio Vargas ISAE (200I2004). Plano de Desenvolvimento Local Integrado e Sustentável, Prefeitura Tabatinga

Riaño Umbarila, E. (2003). Organizando su espacio, construyendo su territorio, transformaciones de los asentamientos Ticuna en la ribera del Amazonas Colombiano, Universidad Nacional de Colombia, Sede Leticia.

Roberts, J.T. (1992). Squatters and Urban Growth in Amazonía, American Geographical Society, Geographical Review, Volume 82, Issue 4, Pages 44I-457

Sadek, M. T. (2000). Constitutional engineering in Brazil: the politics of federalism and decentralization, Rev. bras. Ci. Soc., vol. I5, no.42, p.I53-I54. ISSN 0I02-6909 
Sierra, (2006). Las Fronteras de Colombia, El Tiempo, Junio, Informe Especial

Steinman, R. (2002). A Geografia das Cidades de Fronteira: Um Estudo de Caso de Tabatinga (Brasil) e Letícia (Colômbia), Dissertação Submetida ao Corpo Docente do Programa de Pós-Graduação em Geografia da Universidade Federal do Rio de Janeiro como requisito parcial para obtenção do grau de Mestre Em Ciências (M. Sc.)

SUSAM (2003). GT 3: Políticas públicas e planejamento regional na Amazonía, Workshop, Moderacao: Bertha K. Becker, Neli de Mello

Vargas López de Mesa (2004). Fronteras: espacios conceptuales y materiales en el contexto de la geografía, Fronteras Territorios y Metáforas, Instituto de Estudios Regionales, INER, Universidad de Antioquia., Colombia

UN HABITAT (2000). Millennium Development Goals MDG, Goal 7, Target I I

UN HABITAT (2003). The Challenge of Slums, Global Report of Human Settlements, UN HABITAT

UN Millennium Project (2005), A Home in the City, Task Force on Improving the Lives of Slum Dwellers, UN

Uribe, Juan Carlos (2009) Leticia's waterfront: an amazonian challenge for flood prone area's planning and design, a Design Thesis submitted to the Department of Environmental Sciences \& Landscape Architecture of Chiba University

Vergel, E., (2009), "Ciudades Gemelas en Fronteras Amazónicas: Estudio de Caso Leticia y Tabatinga”, Cuadernos de Vivienda y Urbanismo No. 2, INJAVIU, Universidad Javeriana

\section{Fuentes de Internet:}

www.Amazonía.org, accessed 19/5/2005, Municípios do Amazonas pedem recursos do Ministério das Cidades para elaborar Plano Diretor, Amazonía.

www.uni-tuebingen.de/egwinfo/susam/index.html, accessed 2006, Sustainable Amazonía Structural Change and Policy Options in Rural and Urban Areas, SUSAM is an EU-financed project, carried out by a multilateral and interdisciplinary network of academic institutions and non-governmental organisations from Brazil, Bolivia and the EU

www.citiesalliance.org/index.html, accessed 2006, Cities Alliance Web Page

www.javeriana.edu.co/viviendayurbanismo/pdfs/ /6cnosvir-2.pdf 